\title{
The Growth and Development of the Superior Oblique Muscle and Trochlear Nerve in Juvenile and Adult Goldfish
}

\author{
STEPHEN S. EASTER, JR. \\ Division of Biological Sciences, University of Michigan, Ann Arbor, Michigan 48109 \\ and Institut d'anatomie, Universite de Lausanne, 9 rue du Bugnon, \\ CH1011 Lausanne, Switzerland
}

\begin{abstract}
Superior oblique muscle/trochlear nerve pairs from goldfish of various ages (1-5 years) have been examined light and electron microscopically. The muscle grows by enlargement (longitudinally and transversely) of individual fibers, and by addition of new ones at the rate of about 250/year. The nerve grows by enlargement of fibers, but few and perhaps no new axons are added. The somata enlarge, and the neuromuscular synapses become much more nu. merous. The ratio of muscle fibers to nerve fibers increases from about 5 in the young to about 16 in the old fish.
\end{abstract}

The eye of a goldfish grows throughout the animal's life. The mechanical load on the extraocular musculature therefore increases, and these muscles enlarge accordingly. This report describes the growth-related changes in one of these muscles, in the associated motor nerve, and in the neuromuscular synapses.

Earlier work in fish suggested that the relation between muscles and motor nerves might change with age. If adult teleost muscles grow by adding new fibers, as reported by GreerWalker ('70) and Mazanowska and Kordylewski ('75), then muscular growth would probably be accompanied by creation of new synapses. But the conclusion that new muscle fibers are added was derived from light microscopic fiber counts in large and small animals. It is possible that a population of small muscle fibers, unresolvable light microscopically, might have been overlooked. If they were more numerous in small muscles than in large ones, the apparent addition of fibers could be illusory. The number of muscle fibers must be established electron microscopically.

There is extensive evidence that the central nervous system of adult fish grows by adding new neurons. "Matrix zones," regions of dividing cells, persist in the teleost brain (Kranz and Richter, '70); the teleost retina adds neurons (Muller, '52; Lyall, '57; Johns and Easter, '77; Johns, '77; Kock and Reuter, '78); the lateral line nerve of the trout adds axons
(Thomas, '56); and, in an elasmobranch, the spinal nerves add fibers in both ventral and dorsal roots (Leonard et al., '78). Thus, it is possible that the enlarged muscle might be innervated by new motor nerve fibers, but this question has not been examined directly.

I have counted and measured, in electron micrographs, the muscle and nerve fibers in the superior oblique muscles and trochlear nerves of goldfish of various sizes. With the assumption that the small fish represented earlier stages of the big ones (Johns and Easter, '77), these numbers were then compared in the context of growth.

This particular muscle/nerve pair was chosen for several reasons. (1) The nerve is believed to be exclusively motor, and to serve the superior oblique muscle exclusively (Hadidian and Dunn, '38; Luiten and Dijkstra-de Vlieger, '78). (2) The origin and insertion of the muscle are well localized. The belly is essentially tubular and most likely to have individual fibers extending the full length of the muscle. Therefore a single transverse section should cut through all the fibers and avoid the problems of sampling more complicated muscles (Maxwell et al., '74). (3) Both nerve and muscle are small enough to allow whole cross sections to fit on a single electron microscope grid. (4) The preliminary estimates of numbers: hundreds of muscle fibers (Kilarski and

Received Apr. 6, '79. Accepted June 25, '79. 
Bigaj, '67; Mazanowska and Kordylewski, '75; Davey et al., '75) and tens of nerve fibers (Davey et al.,' '75), are low enough to allow all fibers to be counted.

\section{METHODS}

Common goldfish were obtained commercially, anesthetized by immersion in $0.1 \%$ aqueous tricaine methane sulfonate, and their length and weight were measured. Large fish (body length $>10 \mathrm{~cm}$ tip to tip) were perfused transcardially with chilled buffered aldehydes (2.5\% glutaraldehyde, $2.0 \%$ paraformaldehyde, $0.001 \mathrm{M} \mathrm{Ca}^{++}, 0.067 \mathrm{M} \mathrm{Na}$ cacodylate, $\mathrm{pH} \mathrm{7.2-}$ 7.5), and the superior oblique muscle and trochlear nerve dissected out later in this same chilled solution. Small fish were decapitated, the muscle and the nerve were exposed, and the head was dropped into chilled fixative. After hardening for about an hour, the tissue was dissected out in the same chilled fixative solution. The lens was removed and its diameter measured with a calibrated ocular micrometer. (The lens is a useful indicator of eye size [Hester, '68; Easter et al., '77]). Either left or right, or, in four cases, both left and right muscle/nerve pairs were saved. The tissue was fixed an additional six hours, washed in several changes of buffer for two hours, and post fixed in similarly buffered $2 \% \mathrm{OsO}_{4}$ for six hours. It was then dehydrated, block stained with uranyl acetate, and embedded in plastic (Araldite or a mixture of Araldite and Epon).

Sections were cut with glass knives. Semithin sections $(1 \mu \mathrm{m}$ thick), were mounted on glass microslides and stained with toluidine blue for light microscopy. Thin sections (silver to blue interference colors) were mounted on copper grids for electron microscopy. For all but the largest fish, it was possible to fit a transverse section of the muscle into the open part of a one-hole grid spanned by a formvar film. The largest muscles viewed in this way were nearly $2 \mathrm{~mm}$ wide, a large cutting face for an ultramicrotome; these typically gave the thickest sections (brown to blue interference colors), and were viewed without further staining. The smaller muscles and nerves yielded thinner sections (silver to gold) which were stained on the grid with lead citrate.

The cross sections of both nerve and muscle were reconstructed as photomosaics of electron micrographs of overlapping regions. Depending upon the size of the tissue and the magnification used, the reconstructed sections varied in size from a single print (for a small nerve) to eighty prints (for a large muscle). Final magnification was checked using calibrated standards, and varied from $1,350 \times$ to $5,750 \times$ for nerve, and $1,350 \times$ to $2,120 \times$ for muscle. The sections were reexamined electron microscopically after completion of the photomosaic, to check at higher magnification some regions where the resolution of the photomosaic was inadequate.

Four cross sections of muscles were too big to fit on the grid, and were examined light microscopically. A semithin section was projected through an oil immersion lens onto a screen, and individual muscle fibers were traced from the projected image $(1,012 \times)$.

Quantitative analysis of the tissue involved both counting and measuring individual profiles. In the muscle photomosaics, any membrane-enclosed profile containing a myofibril was scored as a muscle cell. Figures $1 \mathrm{D}, \mathrm{E}$ show examples. In the nerve, both myelinated and unmyelinated fibers were counted. The latter were only discernible when the tissue was examined at magnifications higher than those of the photomosaics. The sizes of the individual profiles were measured with the aid of a digitizing tablet linked to a computer. The contour (e.g., the plasma membrane of a muscle cell) was traced, and the digitized values entered the computer, which calculated the area inside the contour and the diameter of a circle of that area. No correction was made for either shrinkage during preparation of the tissue, or for block compression during sectioning.

End plates were visualized for light miscroscopy, with the acetyl cholinesterase histochemical procedure of Koelle, as modified by Naik ('63), and by tagging the post synaptic receptor molecule with fluorescent alphabungarotoxin (Ravdin and Axelrod, '77).

Intact muscle fibers were viewed in dark field after teasing whole muscles which had been fixed in buffered formalin and soaked in $30 \%$ nitric acid (Maxwell et al., '74).

The brains of most of the animals were saved, fixed in the buffered aldehyde mixture, and embedded in glycomethacrylate plastic. Transverse sections, $20 \mu \mathrm{m}$ thick, were cut through a portion of the mid and hind brains which included the nucleus of the trochlear nerve, and stained with toluidine blue and $1 \%$ $\mathrm{OsO}_{4}$. This nucleus was identified by comparison with earlier reports (Black, '17; Hadidian and Dunn, ' 38 ) and by the swollen and densely staining cell bodies which appeared after sec- 
tion of the trochlear nerve in other goldfish (unpublished observations). It was not possible to determine, in normal tissue, the boundary between the nuclei of the oculomotor and trochlear nerves, therefore, no counts were made of trochlear neurons. The sizes of trochlear neurons from different fish were compared by measuring the diameters of the somata of the five largest cells in corresponding locations near the center of the nucleus. The largest diameter and the diameter perpendicular to that were measured for each cell, and these were averaged to obtain a mean diameter for each animal.

Light microscopic observations were made on a Wild M-20 compound microscope, equipped with drawing tube and camera. Electron microscopic observations were made on a Philips 301 (in Lausanne), and Philips 300 (in Ann Arbor).

\section{RESULTS}

A fixed and embedded superior oblique muscle and trochlear nerve are seen in figure 1A. The muscle originates from the anterior surface of the orbit and inserts superficially to the superior rectus muscle on the dorsal surface of the eye. The nerve exits from the brain at the junction of the midbrain and cerebellum, runs forward, lateral to the tectum, and penetrates from cranium into the posterior side of the orbit. There it runs anteriorly and joins the superior oblique muscle near the middle of the belly. Two or more juxtamuscular branches are always present; they penetrate the muscle near the middle of the belly and close to the insertion.

\section{Structure of the muscle}

The cellular organization of teleost extraocular muscles has been described by others (Kilarski and Bigaj, '67; Mazanowska and Kordylewski, '75; Davey et al., '75). Figures $1 \mathrm{~B} \cdot \mathrm{E}$ illustrate some of these features and others to be treated below. An additional reason for including figures $1 D, E$ is to demonstrate that individual muscle fibers are readily identified (by the presence of myofilaments) and distinguished from neighbors (by the presence of the plasma membrane) even in sections quite thick by usual standards of electron microscopy.

On the basis of ultrastructure, there are two types of muscle fibers: red and white. The former have many mitochondria, the latter, rather few. The white fibers are generally the larger, but there is considerable overlap in size. The two types are segregated to different regions of the muscle. In the following account, interfiber differences are ignored.

\section{Growth of the muscle}

The orbital contents of large and small fish are roughly conformal, so that the muscles in the larger fish are both longer and thicker. The difference in thickness is evident in figures 1B,C, cross sections of two muscles, and in figure $2 \mathrm{~A}$, a plot of cross section vs. lens diameter for all muscles examined. The cross sections enlarge because of two factors: enlargement of the existing fibers, and addition of new ones. The histograms in figure $2 B$ illustrate both of these changes by comparing two muscles; the larger muscle has generally larger fibers (median diameter: $12-13 \mu \mathrm{m}$ vs. 6-7 $\mu \mathrm{m}$ for the smaller), and more of them. In figure $2 \mathrm{C}$, drawn from all muscles, the systematic increase in fiber number is illustrated, confirming the conclusion (from light microscopy) of Mazanowska and Kordylewski ('75). Note that all muscles except the four with lens diameters of 3.5 or $3.6 \mathrm{~mm}$ were derived from electron micrographs.

This conclusion rests on the assumption that a single cross section through the center of the muscle sampled all the fibers. This might be incorrect if some fibers branched or if they terminated at points other than the origin or the insertion. Light microscopic examination of teased muscle revealed that the fibers all ran closely parallel, as suspected from the tubular shape of the muscle. Examination at high magnification $(500 \times)$ showed no fibers which either terminated or branched. Many individual fibers were teased out, intact, and were as long as the muscle. Branched fibers were also sought in tangential sections, both plastic semithin sections $(1 \mu \mathrm{m}$ thick) and frozen sections $(40-80 \mu \mathrm{m}$ thick) cut for histochemistry. Again, none were found. Finally, two muscles were cut transversely at different levels, extending from near the insertion to near the middle of the belly. If fibers branched or terminated in the belly, there should be different numbers cut at different levels. The cross sections were reconstructed as electron micrographic photomosaics, and the muscle fibers counted. In one muscle, the numbers were $414,417,415$ and 414 ; in the other, 454,452 , and 451 . The small variability most probably represented errors in identification of very small profiles, and not 
real differences in fiber number. I conclude that branched or short fibers are not numerous enough to invalidate the method.

The rate of fiber addition may be estimated as follows. The very largest animals in figure $2 \mathrm{C}$ were about $20 \mathrm{~cm}$ long, and had about 1,400 fibers. The smallest, about $5 \mathrm{~cm}$, had about 400. The ages of these fish are about four to five years and less than one year, respectively (Johns and Easter, '77). Therefore, in rough figures, 1,000 fibers were added over four years, approximately one every one and onehalf days.

\section{Structure of the nerve}

In most of the animals examined, the trochlear nerve ran alone in the orbit. The fibers were predominantly or exclusively myelinated (see below), were packed loosely, and covered a wide range of sizes as shown in figures $3 A, B$. In a few cases ( 3 of 32 ), another, distinctly different, nerve accompanied the trochlear. This other nerve was characterized by a relatively uniform population of small fibers, tightly packed, with a great many Schwann cells. In two cases, the nerve accompanied the trochlear all the way to the muscle, then ran toward and past the insertion without penetrating. In the other case, it left the trochlear nerve before reaching the muscle. The identity of this nerve was never established, but it was surely not a branch of either the oculomotor or abducens nerves since they resembled the trochlear (unpublished observations).

Of the 21 trochlear nerves which were examined at both low and high magnification, six contained no processes which could be interpreted as nonmyelinated fibers, while the other 15 held between 3 and 35 . Generally, they were more numerous in the larger fish.

The possibility that fibers branch in the nerve was assessed by making multiple cross sections. In one case, a nerve was dissected in its entirety from central origin to termination in the muscle, and 12 sections, roughly evenly spaced, were examined. In other cases, only the intraorbital segment was examined. In all cases, the number of myelinated fibers in a given nerve was constant except at very distal positions, very close to the muscle, where the number increased. Although a branching nerve fiber was never visualized, this preterminal increase in myelinated fibers was taken as evidence for branching. Nonmyelinated fibers were not examined in this context.

\section{Growth of the nerve}

In the quantitative analysis which follows: (1) All numbers were derived from single cross sections of nerves taken at an intraorbital level as far central as possible, to avoid the problem of branching fibers. (2) The nonmyelinated fibers were ignored. (3) None of the results came from nerves associated with the extra nerve of unknown origin.

The trochlear nerves in the large animals were both longer and thicker than in the small fish. The axoplasmic cross sections of individual myelinated fibers were measured, summed for each nerve, and plotted in figure $2 \mathrm{D}$. The evident increase was attributable mainly to enlargement of existing fibers, as figures $2 \mathrm{E}, \mathrm{F}$ and figures $3 \mathrm{~A}, \mathrm{~B}$ show. The histograms of fiber diameters from two groups of nerves show that the larger fish had larger fibers (median diameter: $3.5-4.0 \mu \mathrm{m}$ vs. $2.5-3.0 \mu \mathrm{m}$ for the small). The number of myelinated fibers, on the other hand, did not covary with the lens diameter. The least squares regression line has a small positive slope, but the low correlation coefficient prevented any firm conclusion to whether or not the nerve added fibers. When large fish (lens diameter $\geqslant 3.0$ $\mathrm{mm}$ ) were compared with small fish (lens diameters $\leqslant 2.0 \mathrm{~mm}$ ), the mean numbers $( \pm$ S. D. $)$ were $90.1 \pm 13.9(\mathrm{~N}=8)$ and $78.2 \pm$ $12.5(\mathrm{~N}=10)$ for the large and small fish respectively. When compared by student's t-test, with Bessell's correction for small samples, $\mathrm{p}>0.05$.

The numbers of fibers in two nerves taken from the same animal were closer than in two nerves taken from different animals with sim. ilar lens diameters $( \pm 0.1 \mathrm{~mm})$. The latter differed by as much as $30 \%$ of the mean, the former, by no more than $10 \%(54,60 ; 67,70$; 72,74 ; and 72,78 in pairs from the same animals).

Examinations of the brains revealed that the trochlear neurons were larger in the larger fish, as illustrated in figure $3 \mathrm{C}-\mathrm{F}$. The mean diameter of trochlear somata was 16.8 $\mu \mathrm{m}$ for small fish (lens diameter: $1.6-2.0 \mathrm{~mm}$ ) and $22.4 \mu \mathrm{m}$ for larger ones (lens diameter: 2.5-2.8 mm).

In summary, the trochlear nerve grows by developing longer and thicker axons. The somata of the trochlear neurons enlarge as well. The nerve adds very few, and perhaps no, new axons. The ratio: (number of muscle fibers/number of nerve fibers) increased from about 5 in the small fish to about 16 in the 
largest ones. This last number is probably an underestimate, as it was derived from light microscopic counts of muscle fibers.

If all the new muscle fibers are to be innervated, then the relatively constant number of motor nerve fibers must form new end plates. This was checked histochemically by marking the acetyl cholinesterase found at end plates. The distribution of reaction product in muscles from both small and large fish was examined light microscopically, sketched with the aid of a drawing tube, and is illustrated in figure 4. Note, first, that the reaction sites are distributed throughout the length of the muscle in each section, and that they are approximately equally numerous in all sections from the same muscle. This diffuse and ubiquitous innervation has been noted by others (Davey et al., '75; Scott, '77). The possibility that the staining was an artifact was checked in three ways. First, sections incubated in the presence of eserine, an inhibitor of acetyl cholinesterase, showed no reaction product. Second, sections of other muscles were examined electron microscopically at several levels: near the insertion, near the site of entry of the nerve, and closer to the origin. In all sections, regardless of position, there were abundant end plates. Third, some muscles were colabeled with fluorescent alpha-bungarotoxin, a specific binding agent for nicotinic acetyl choline receptor sites. These were coextensive with the vast majority of the cholinesterase-positive sites, the result expected if the cholinesterase histochemistry revealed end plates.

Thus, the conclusion seems inescapable that new synapses are made as the muscle grows. Some are added to preexisting muscle fibers, others are first synapses on new fibers. Figure 4 suggests an enormous amount of sprouting by the nerve fibers.

\section{DISCUSSION}

These results are summarized as follows. The muscle grows by addition of new fibers and by enlargement of the preexisting ones. The nerve and motor nucleus grow by enlargement of preexisting axons and somata, but few, and perhaps no, new axons are added. The total number of synapses in the muscle increases enormously.

Concomitant hypertrophy of muscle and motor nerve has been reported previously, in mammals, but the effects were not nearly so large as these. Edds ('50) induced hypertrophy in the rat soleus muscle by denervating its synergists. The fiber size spectra from both the soleus muscle and its motor nerve shifted to higher values, but the mean increase was much smaller than the naturally occurring growth reported here. Edds suggested that the neural hypertrophy resulted from increased axoplasmic flow, and the idea that the larger end organ required more axoplasmic transport is still an attractive one. If some axonally transported "trophic factor" (Varon and Bunge, '78) were essential to maintenance of the neuromuscular system, then it is not unreasonable to suppose that a large muscle would require (or produce) more of it, and the larger axons could probably carry more.

The demonstration that somata, fibers, and terminal arbors all increased in size is also consistent with other reports. In one of these, cat motor neurons were compared electrophysiologically, and large somata were correlated with large fibers and large motor units (McPhedran et al., '65). In another, Edds ('49) induced terminal arbors in rats to enlarge, and observed that this was coupled with hypertrophy of the fibers. In this case, somata were not measured. This last study, and others like it, in which nerve fibers had to be induced to sprout, are obviously quite different from the case described here. In the superior oblique muscle of goldfish, fibers evidently sprout continually in order to innervate the ever-grow. ing end organ. It would be interesting to learn if these muscles contain the "sprouting fraction" recently extracted by Tweedle and Kabara ('77) from partially denervated muscle.

None of the observations described here give a clue about where the new muscle fibers appear or how they are generated; i.e., by fiber splitting or de novo fusion of precursor cells.

\section{Functional analysis of growth}

The role of the superior oblique muscle is to rotate the eye about the optic axis, by depressing the anterior side of the globe, thus compensating for upward-directed tilt of the head (Traill and Mark, '70). The eye can assume a continuum of positions, and it is important to remember that this is accomplished through polyneuronal innervation of the muscles, many of which neither spike nor twitch (Takeuchi, '59; Hudson, '69; Scott, '77). This is in marked contrast to the singly-innervated motor units common to much of mammalian and avian skeletal muscle, and resembles more closely crustacean muscle, in which a 
tiny number of motor axons control the tension of many fibers (Prosser, '73). Evidently, polyneuronal innervation can produce a finely graded range of tensions with relatively few nerve fibers. The relative unimportance of the number of fibers probably accounts for why the measured number varied so widely from individual to individual, and why the larger fish added so few, if any, new ones.

The growth of the muscle strengthens it and enables it to continue to move the larger eye at comparable speeds over a comparable range of positions. The muscle adds new fibers, rather than simply enlarging the existing fibers as happens in juvenile and adult mammals (reviewed by Goldspink, '72; Ontell and Dunn, '78). Perhaps the different mode of growth is a consequence of the much greater magnitude of growth experienced by fish. Mammals typically grow postnatally by a factor of 20-30. An example is a human, with birthweight of about $3 \mathrm{~kg}$, and adult weight of $50-100 \mathrm{~kg}$. The fish grows by many orders of magnitude more. A goldfish hatchling weighs a few milligrams; five years later, it weighs hundreds of grams and continues to grow. In fact, the superior oblique muscles of the largest fish examined in this report were larger than the entire hatchling. It is probably impossible for an animal to begin life outside the egg with enough muscle cells to sustain growth by a factor of $10^{4}-10^{5}$ through hypertrophy alone.

How has the function of the nerve fibers been altered by enlargement? For one thing, larger axons conduct impulses more rapidly than small ones. Since the distance between motor nucleus and muscle increases with growth, the increased fiber size is probably adaptive, as it works against increased conduction delay. A second functional change is an increased capacity for axonal transport, mentioned earlier.

\section{Points of uncertainty}

Firstly, the variable presence of processes resembling non-myelinated nerve fibers is unclear. Perhaps they are new motor fibers, added too recently to have been myelinated. If so, it is difficult to understand why they should be more prevalent in the older animals, in which the nervous system is thought to grow more slowly (Richter and Kranz, '70). Alternatively, the processes may not have been neural, but glial, as Payer ('79) has described in peripheral nerve of rat.
Secondly, if sensory receptors were present in the muscle, the analysis would be slightly changed. All attempts to reveal muscle spindles in fish have been unsuccessful, but some muscle receptors have been identified in the tendons of the fin musculature in both elasmobranchs and teleosts (reviewed by Barker, '74). Luiten ('79) suggests that all extraocular muscles in carp have sensory fibers. The present investigation showed no spindles in the muscle, nor did it reveal anything resembling the putative sensory receptors in other fish. Nonetheless, it is possible that sensory receptors exist in the superior oblique muscle, and that some fraction of the trochlear axons were either afferent from them or efferent (gamma-like) to them. If this were so, then the ratio of muscle fibers to motor nerve fibers would have to be raised, but the conclusion that this ratio changes with growth would still stand.

Finally, there is some disagreement about numbers of nerve fibers and somata. Leonard and Willis ('79) reported that the numbers of somata and axons were nearly identical in the stargazer, another teleost. Hadidian and Dunn ('38) reported that in small goldfish, the trochlear nerve and nucleus had comparable numbers of fibers and somata, respectively. Their estimate, about 150, was considerably larger than my fiber counts, and I can not explain the discrepancy, as they used light microscopical methods which should have underestimated, not overestimated, numbers. Luiten and Dijkstra-de Vlieger ('78) reported that the trochlear nucleus of the closely related carp contained 29-63 somata. They did not count nerve fibers. If this small number of somata is to be reconciled with my larger number of fibers, it suggests that individual somata have more than one axon. Sohal and Weidman ('78) have reported that such is the case in duck. The discrepancy in numbers might also be attributable to the species difference, or to the inadequate back filling of some (e.g., the smaller) axons by the histochemical marker, horseradish peroxidase, used by Luiten and Dijkstra-de Vlieger.

\section{CONCLUSION}

The superior oblique muscle and trochlear nerve of goldfish grow even in juveniles and adults. Three features of this growth are unusual as they are generally thought to occur naturally only in immature animals. These 
features are the addition of new muscle fibers, new nerve terminals, and new synapses.

\section{ACKNOWLEDGMENTS}

I thank H. Van der Loos for useful discussions and suggestions, M. Gissler and R. Miller for help with the graphic analysis, D. Axelrod for the fluorescent alpha bungarotoxin and work related thereto, M. Gaillard, S. Scherer, and P. Kish for technical assistance, and D. Madrid for typing the manuscript. This work was supported by grants from the Swiss National Science Foundation (3.776) to Professor Van der Loos and from the U. S. Public Health Service (EY-00168) and from IBRO. Suisse to myself.

\section{LITERATURE CITED}

Barker, D. 1974 The morphology of muscle receptors. In: Handbook of Sensory Physiology. Vol. III/2. C. C. Hunt, ed. Springer-Verlag, New York, pp. 1-191.

Black, D. 1917 The motor nuclei of the cerebral nerves in phylogeny: a study of the phenomenon of neurobiotaxis. Part I. Cyclostomi and pisces. J. Comp. Neur., 27: 267-564.

Davey, D. F., R. F. Mark, L. R. Marotte and U. Proske 1975 Structure and innervation of extraocular muscles of Carassius. J. Anat. (London), 120: 131-143.

Easter, S. S., P. R. Johns and L. Baumann 1977 Growth of the adult goldfish eye. I. Optics. Vision Res., 16: 469-476.

Edds, M. V. 1949 Experiments on partially deneurotized nerves. II. Hypertrophy of residual fibers. J. Exp. Zool., 112: 29-47.

1950 Hypertrophy of nerve fibers to functionally overloaded muscles. J. Comp. Neur., 93: 259-275.

Goldspink, G. 1972 Postembryonic growth and differentia. tion of striated muscle. In: The Structure and Function of Muscle. Vol. 1. Part 1, Structure. Second Ed. G. H. Bourne, ed. Academic, New York, pp. 181-236.

Greer-Walker, M. 1970 Growth and development of the skeletal muscle fibers of the cod (Gadus mochua L.). J. Cons. Perm. Int. Explor. Mer., 33: 228-244.

Hadidian, Z., and M. S. Dunn 1938 Localization in the oculomotor nuclei of the goldfish. J. Comp. Neur., 68: 191-203.

Hester, F. J. 1968 Visual contrast thresholds of the goldfish (Carassius auratus). Vision Res., 8: 1315-1336.

Hudson, R. C. L. 1969 Polyneuronal innervation of the fast muscles of the marine teleost Cottus scorpius L. J. Exp. Biol., 50: 47-67.

Johns, P. R. 1977 Growth of the adult goldfish eye. III. Source of new retinal cells. J. Comp. Neur., 176: 343-358.

Johns, P. R., and S. S. Easter 1977 Growth of the adult goldfish eye: II. Increase in retinal cell number. J. Comp. Neur., 176: 331-342.

Kilarski, W., and J. Bigaj 1969 Organization and fine structure of extraocular muscles in Carassius and Rana. Z. Zellforsch., 94: 194-204.

Kock. J. H., and T. Reuter 1978 Retinal ganglion cells in the crucian carp (Carassius carassius). I. Size and number of somata in eyes of different size. J. Comp. Neur., 179: 535-548.

Kranz, D, and W. Richter 1970 Autoradiographische Untersuchungen uber die Lokalisation der Matrixzonen des Diencephalons von juvenilen und adulten Lebistes retic- ulatus (Teleostei). Z. mikrosk, anat. Forsch., 82: 42-66. Leonard, R., R. E. Coggeshall and W. D. Willis 1978 A documentation of an age related increase in neuronal and axonal numbers in the stingray, Dasyatis sabina, Leseuer. J. Comp. Neur., 179: 13-22.

Leonard, R. B., and W. D. Willis 1979 The organization of the electromotor nucleus and extraocular motor nuclei in the stargazer (Astroscopus y.graecum). J. Comp. Neur., 183: $397-414$

Luiten, P. G. M. 1979 Proprioceptive reflex connections of head musculature and the mesencephalic trigeminal nucleus in the carp. J. Comp. Neur., 183: 903-912.

Luiten, P. G. M., and H. P. Dijkstra-de Vlieger 1978 Extraocular muscle representation in the brainstem of the carp. J. Comp. Neur., 179: 669-676.

Lyall, A. H. 1957 The growth of the trout retina. Quart. J. Microsc. Sci., 98: 101-110.

Maxwell, L. C., J. A. Faulkner and G. J. Hyatt 1974 Estimation of number of fibers in guinea pig skeletal muscles. J. Appl. Physiol., 37: 259-264.

Mazanowska, J., and L. Kordylewski 1975 Number and djmensions of muscle fibers in extraocular muscles of the gudgeon Gobio gobio (L.). Acta Biol. Cracov. Ser. Zool., 18: 221.228 .

McPhedran, A. M., R. B. Wuerker and E. Henneman 1965 Properties of motor units in a homogeneous red muscle (soleus) of the cat. J. Neurophysiol., 28: 71-84.

Muller, H. 1952 Bau und Wachstum der Netzhaut des Guppy (Lebistes reticulatus). Zool. Jb., 63: 275-324.

Naik, H. T. 1963 Technical variations in Koelle's histochemical method for demonstrating cholinesterase activity. Quart. J. Microsc. Sci., 104: 89-100.

Ontell, M., and R. F. Dunn 1978 Neonatal muscle growth: a quantitative study. Am. J. Anat., 152: 539-556.

Payer, A. F. 1979 An ultrastructural study of Schwann cell response to axon degeneration. J. Comp. Neur., 183: 365-384.

Prosser, C. L. 1973 Comparative Animal Physiology. Third ed. Saunders, Philadelphia, pp. 753-760.

Ravdin, P., and D. Axelrod 1977 Fluorescent tetramethyl rhodamine derivatives of alpha-bungarotoxin: preparation, separation, and characterization. Analytical Biochem., 80: 585-592.

Richter W., and D. Kranz 1970 Die Abhängigkeit der DNSSynthese in den Matrixzonen des Mesencephalons vom Lebensalter der Versuchtiere (Lebistes reticulatus Teleostei). Autoradiographische Untersuchungen. Z. microsk.-anat. Forsch., 82: 76-92.

Scott, S. A. 1977 Maintained function of foreign and appropriate junctions on reinnervated goldfish extraocular muscles. J. Physiol., 268: 87-109.

Sohal, G. S., and T. A. Weidman 1978 Development of the trochlear nerve: loss of axons during normal ontogeny. Brain Res,, 142: 455.465.

Takeuchi, A. 1959 Neuromuscular transmission of fish skeletal muscles investigated with intracellular microelectrodes. J. Cell. Comp. Physiol., 54: 211-220.

Thomas, P. K. 1956 Growth changes in the diameter of peripheral nerve fibers in fishes. J. Anat. (London), 90: 5-14.

Traill, A. B., and R. F. Mark 1970 Optic and static contributions to ocular counterrotation in carp. J. Exp. Biol., 52: $190-124$

Tweedle, C. D., and J. J. Kabara 1977 Lipophilic nerve sprouting factor(s) isolated from denervated muscle. Neuroscience Letters, $6:$ 41-46.

Varon, S. S., and R. P. Bunge 1978 Trophic mechanisms in the peripheral nervous system. Ann. Rev. Neurosci., 1: 327-362. 


\section{Abbreviations}

som, superior oblique tn, trochlear nerve muscle

$\mathrm{v}$, ventricle

\section{PLATE 1}

\section{EXPLANATION OF FIGURES}

1 Superior oblique muscle. The calibration line in $\mathrm{A}$ applies to all subfigures, with the values: $\mathrm{A}, 1 \mathrm{~mm} ; \mathrm{B}$ and $\mathrm{C}, 225 \mu \mathrm{m}$; D and $\mathrm{E}, 6.4 \mu \mathrm{m}$.

A Part of a right superior oblique muscle (som) and trochlear nerve (tn) from a large animal (lens diameter $=3.7 \mathrm{~mm}$ ). Origin toward the right, insertion left.

B, C Semithin transverse sections from small and large animals, respectively (lens diameter $=2.0,3.6 \mathrm{~mm}$ ). Small fibers to the right. large fibers left. Trochlear nerves from these two muscles are shown in figures $3 \mathrm{~A}, \mathrm{~B}$.

D, E Electron micrographs from the zones of large and small fibers, respectively, of the muscle shown in $\mathrm{C}$. The white " $\mathrm{O}$ " indicates those profiles scored as muscle fibers. 


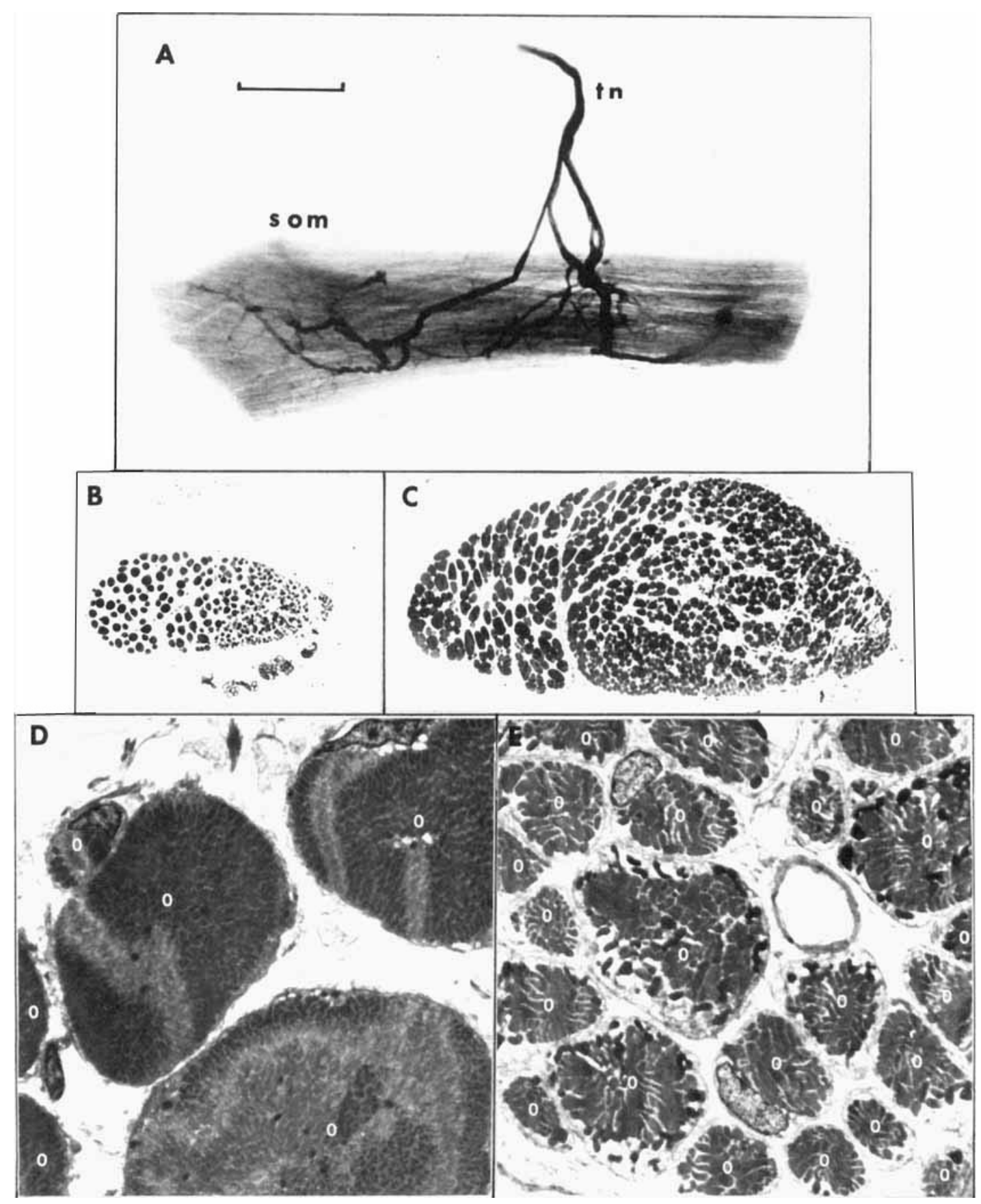




\section{PLATE 2}

\section{EXPLANATION OF FIGURES}

2 Quantitative aspects of superior oblique muscles (A, B, C) and trochlear nerves (D, E, F).

A Area of transverse section near the middle of the belly. $N=18$. Least squares linear regression line (and correlation coefficient); $Y=18.9 \times 10^{4} \mathrm{X}-27.1 \times 10^{4}$ $(\mathbf{r}=0.88)$

B A pair of muscle fiber diameter histograms from one large and one small animal. The ordinate gives numbers of fibers in each size class.

C Numbers of muscle fibers. All except the four with L. D. $=3.5$ or $3.6 \mathrm{~mm}$ were counted in electron micrographs. $\mathrm{N}=19$. Least squares linear regression line (and correlation coefficient): $Y=570 X-589(r=0.94)$.

D Summated areas of cross sections of trochlear nerve fibers. $N=24$. Least squares linear regression line (and correlation coefficient): $Y=779 \mathrm{X}-310(\mathbf{r}=0.79)$.

E A pair of nerve fiber diameter histograms, comparing a group of 12 small fish and 5 large ones. The ordinate gives percentage of the fibers in either group which fall in each class size.

F Numbers of nerve fibers. $\mathrm{N}=26$. Least squares linear regression line (and correlation coefficient): $\mathrm{Y}=6.20 \mathrm{X}+68.1(\mathrm{r}=0.35)$. 


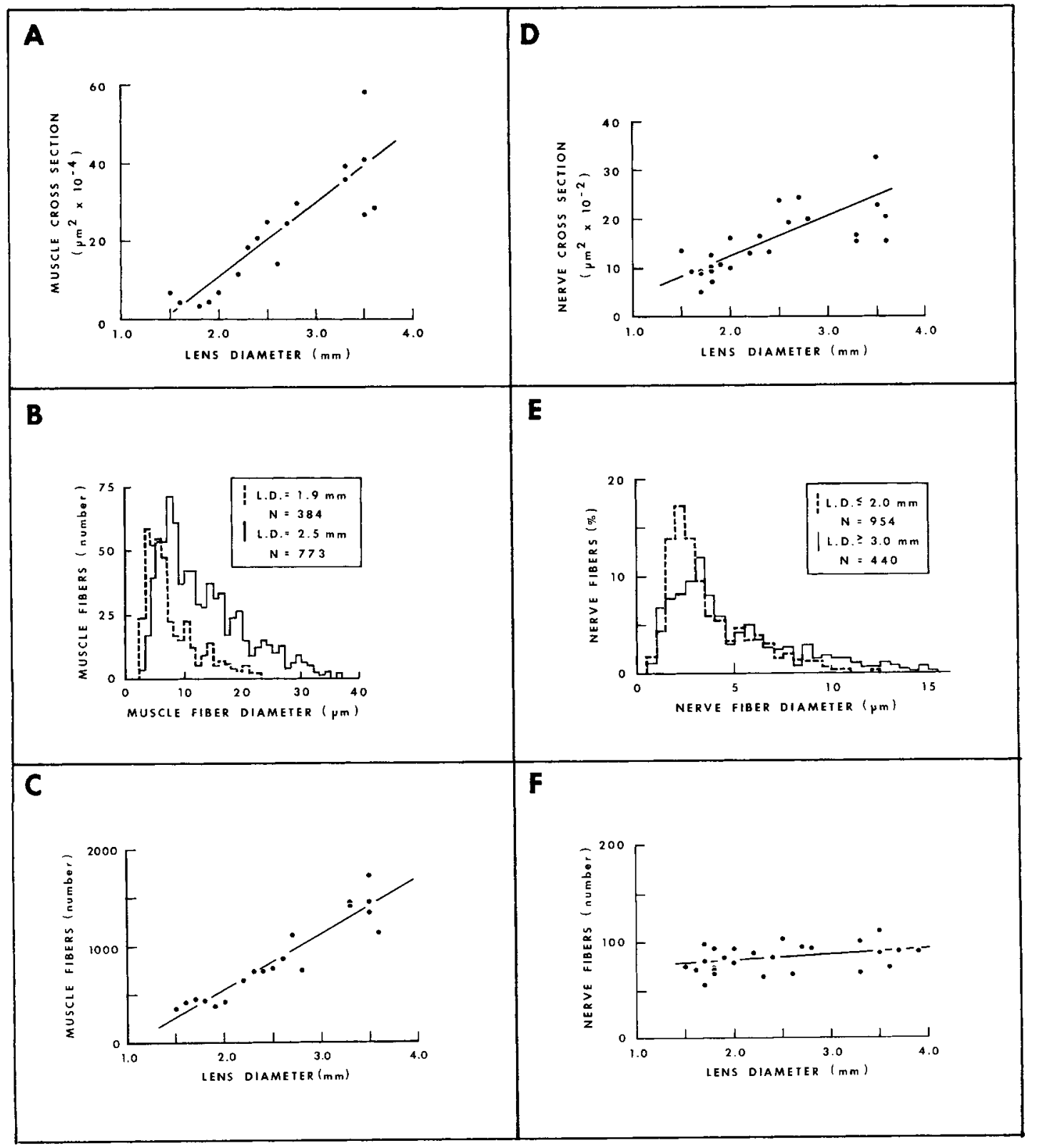


PLATE 3

EXPLANATION OF FIGURES

3 Trochlear nerve and neurons. Calibration line in A applies to all subfigures, with the values: $\mathrm{A}, \mathrm{B}, 25 \mu \mathrm{m} ; \mathrm{C}, \mathrm{D}, 129 \mu \mathrm{m} ; \mathrm{E}, \mathrm{F}, 21 \mu \mathrm{m}$.

A, B Electron micrographs of transverse sections of trochlear nerves from a small and a large animal, respectively (lens diameter $=2.0,3.6 \mathrm{~mm}$ ). Light micrographs of the muscles innervated by these nerves are shown in figure $2 \mathrm{~B}$ and $\mathrm{C}$.

C, D Light micrographs of transverse sections of the brains of a small and a large animal, respectively (lens diameter $=1.6,2.8 \mathrm{~mm}$ ) through corresponding regions of the nuclei of the trochlear nerves. Arrows indicate medial longitudinal fasciculus, $\mathrm{v}=$ ventricle.

E, F Light micrographs, more highly magnified views of the regions enclosed by the boxes in C and D, respectively, to show somata of the trochlear neurons. 


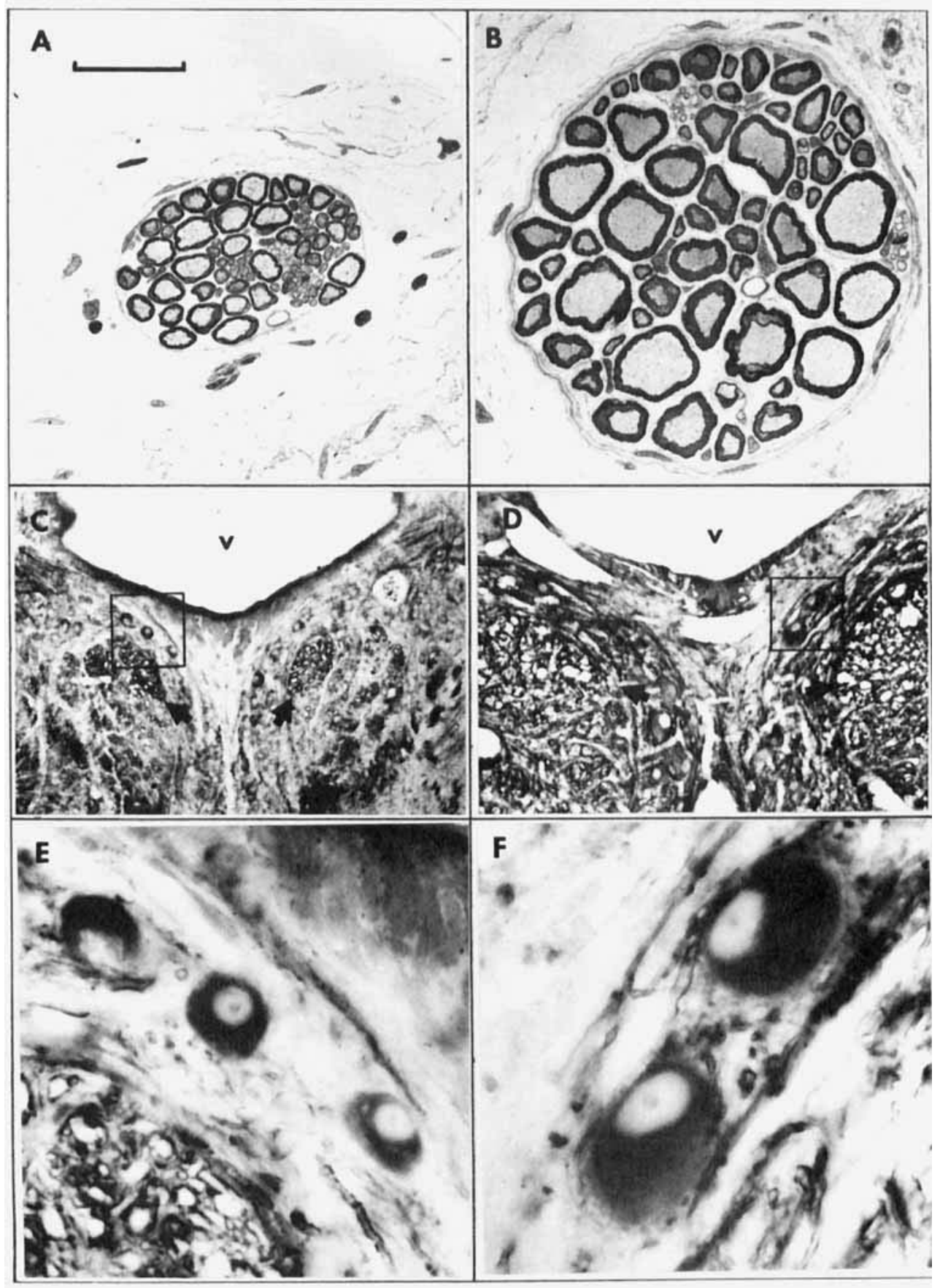




\section{PLATE 4}

\section{EXPLANATION OF FIGURES}

4 A-F Distribution of motor end plates. Camera lucida drawings of three longitudinal sections through superior oblique muscles of a small animal (A-C; lens diameter $=1.7 \mathrm{~mm}$ ) and a large one $(\mathrm{D}-\mathrm{F}$; lens diameter $=3.2 \mathrm{~mm}$ ). Each line represents a region of acetylcholinesterase activity. Calibration line in $\mathrm{F}$ apples to all subfigures, and equals $1 \mathrm{~mm}$. 


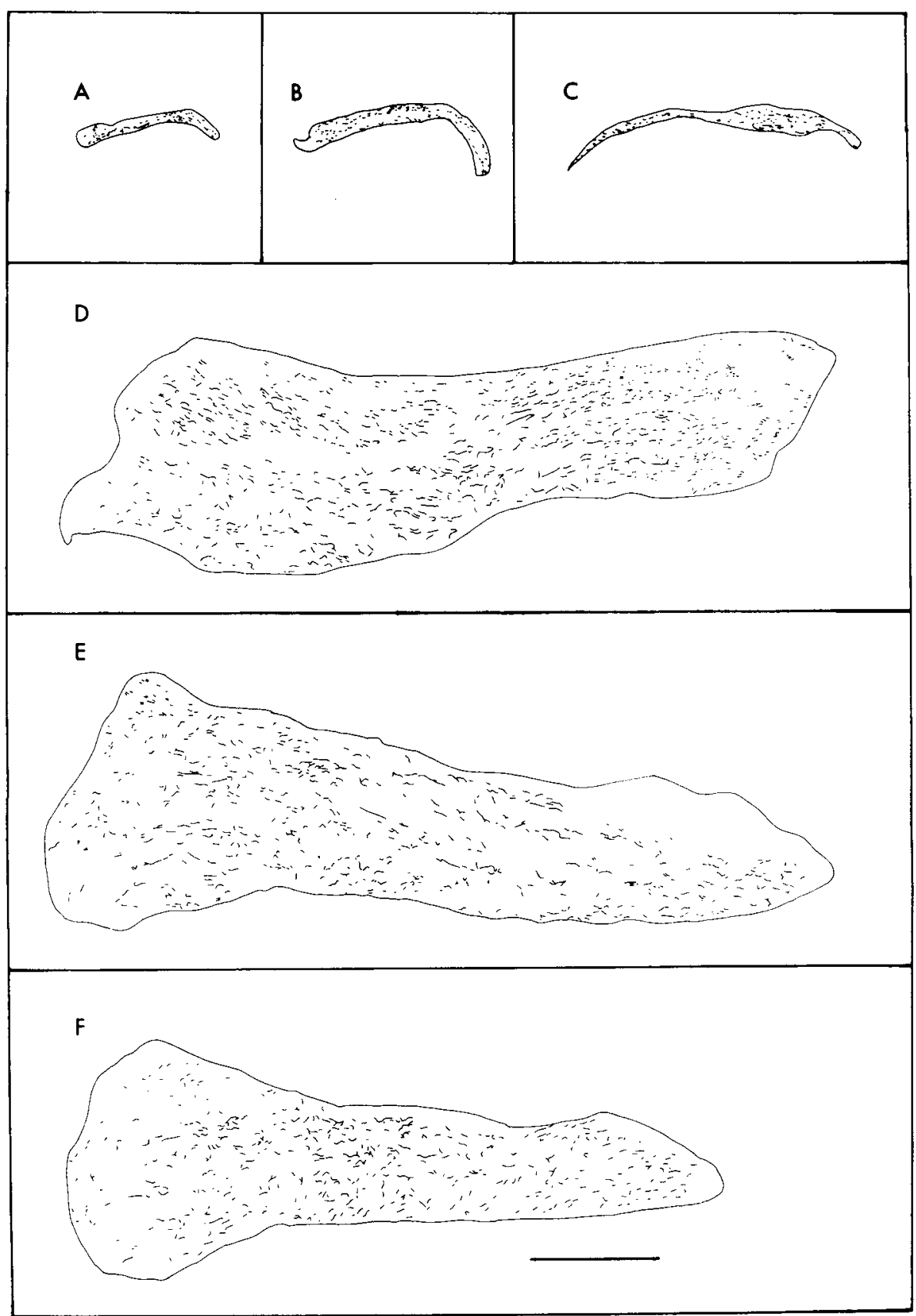

